With compliments of the Author 


\title{
$Z$-Selective Dimerization of Aromatic Terminal Alkynes Catalyzed by an Iridium(I)-N-Heterocyclic Carbene-Phosphine System
}

\author{
Calum D. Forsyth, William J. Kerr,* Laura C. Paterson \\ Department of Pure and Applied Chemistry, WestCHEM, University of Strathclyde, 295 Cathedral Street, Glasgow, G1 1XL, Scotland, UK \\ Fax +44(141)5484246; E-mail: w.kerr@strath.ac.uk
}

Received: 10.01.2013; Accepted after revision: 30.01.2013

\begin{abstract}
The development of an iridium-catalyzed regio- and stereoselective dimerization process has enabled the formation of $(Z)$ enyne products. More specifically, low catalyst loadings of an iridium(I) complex, featuring a bulky N-heterocyclic carbene-phosphine ligand combination, has been successfully employed in this selective head-to-head dimerization of terminal alkynes via $\mathrm{C}-\mathrm{H}$ activation.
\end{abstract}

Key words: alkynes, enynes, dimerization, $\mathrm{C}-\mathrm{H}$ activation, iridium

The dimerization of terminal alkynes is one of the most expedient and atom-economical routes towards conjugated enyne compounds. ${ }^{1}$ Indeed, such products are versatile building blocks in organic synthesis, ${ }^{2}$ as well as in materials science. ${ }^{3}$ As such, a number of transition metals have emerged within catalyst systems for this transformation, including gold, ${ }^{4}$ palladium,${ }^{5}$ iron, ${ }^{6}$ nickel,${ }^{7}$ iridium, ${ }^{8}$ and, very recently, zirconium. ${ }^{9}$ However, the establishment of methods that deliver desirable levels of regio- and stereocontrol provides a continuing challenge within this area. Scheme 1 displays the potential enyne isomers obtainable via this dimerization process. In addition to these products, competing cyclotrimerization ${ }^{10}$ or butatriene formation $^{8 \mathrm{c}, \mathrm{d}, 11}$ are also observed reaction outcomes. Nevertheless, the formation of branched enynes, that is, headto-tail coupled products $\mathbf{A}$, has been readily achieved via $\mathrm{Au}$ and Pd catalysis. ${ }^{4,5}$ Additionally, the head-to-head coupled $(E)$-enynes B have been prepared without incident, employing a range of metal catalysts. ${ }^{6,7,8 b-d, 12}$

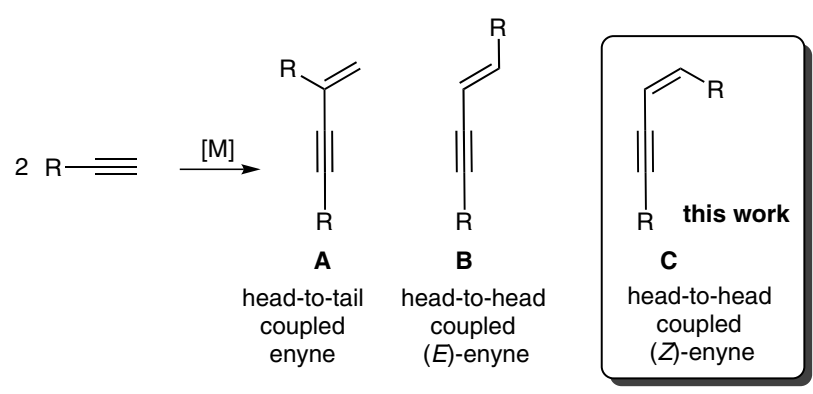

Scheme 1 Homodimerization of terminal alkynes

SYNLETT 2013, 24, 0587-0590

Advanced online publication: 18.02.2013

DOI: 10.1055/s-0032-1318271; Art ID: ST-2013-D0035-L

(C) Georg Thieme Verlag Stuttgart · New York
In contrast, the $Z$-selective head-to-head homodimerization of terminal alkynes $\mathbf{C}$ is much less common. Whilst synthetic methods have emerged towards a $Z$-selective pathway, ${ }^{8 \mathrm{a}, \mathrm{c}, \mathrm{d}, 9,12 \mathrm{~b}, 13}$ this arena is still relatively underdeveloped. Indeed, there remains a requirement for a robust and reliable reaction protocol for the dimerization of alkynes over a wide range of substrates to form products such as $\mathbf{C}$. Herein we now report a catalytic process for the delivery of head-to-head dimerized alkyne products with $Z$-selectivity using low loadings of transition-metal catalyst.

Recent research within our laboratory has led to the preparation and application of a series of novel iridium(I) complexes featuring both a sterically demanding N-heterocyclic carbene (NHC) along with an appreciably encumbered phosphine ligand (Figure 1). ${ }^{14}$ Such complexes are readily handled, and we have previously showcased the ability of these complexes to facilitate hydrogen isotope exchange by arene $\mathrm{C}-\mathrm{H}$ activation, ${ }^{14}$ with activity far in excess of the current industry standard, Crabtree's catalyst. ${ }^{15}$ More recently, work within our laboratories has highlighted the extremely efficient performance of these novel complexes in selective hydrogenation reactions. ${ }^{16}$

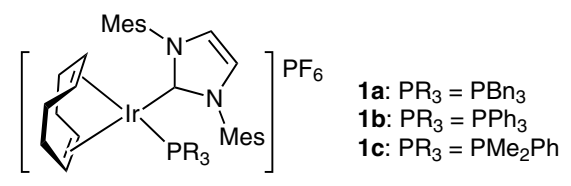

Figure 1 Iridium(I) complexes bearing a bulky NHC-phosphine ligand combination

As part of our ongoing endeavors to extend the applicability of our emerging catalyst series, we wished to investigate their ability to promote a selective alkyne dimerization process through activation of a terminal alkyne $\mathrm{C}-\mathrm{H}$ bond (Scheme 2). Indeed, we anticipated that the specific electronic and steric properties imparted by the mixed NHC-phosphine ligand system would lead to efficient alkyne coupling.

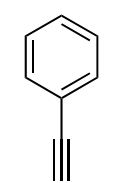

2

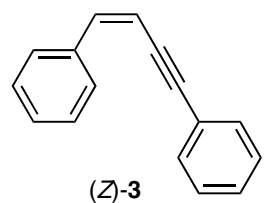

$(Z)-3$
Scheme 2 Head-to-head homodimerization of terminal alkynes 
In order to evaluate this hypothesis, alkyne homodimerization, promoted by complexes $\mathbf{1 a - c}$, was investigated using phenylacetylene as our starting substrate (Table 1). Pleasingly, on our initial application, complex 1a promoted the desired transformation at a catalyst loading of only $2.4 \mathrm{~mol} \%$, with $87: 13$ selectivity towards the $Z$-isomer, albeit in a modest $29 \%$ yield. Notably, none of the head-totail homodimerized product was observed. Complexes $\mathbf{1 b}$ and 1c were also screened; whilst, again, none of the headto-tail isomer was identified, lower $Z / E$ ratios and chemical yields were exhibited. In all of these initial processes, appreciable byproduct formation was also noted. From our previous studies, ${ }^{14,16}$ complex 1a has, to date, proved to be the most versatile of this new group of catalysts. Accordingly, we were encouraged by the initial result in this study with 1a to further probe the synthetic utility of this novel species.

Table 1 Homodimerization Studies with Complexes 1a-c

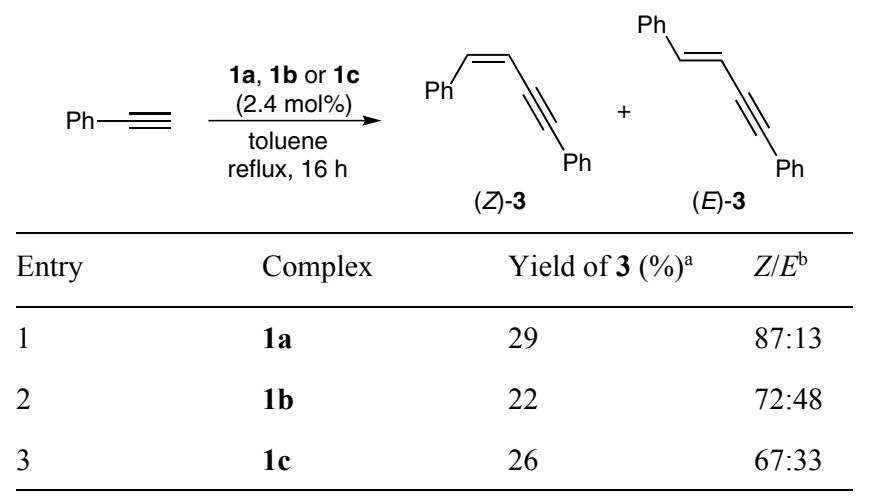

${ }^{a}$ Isolated yield.

${ }^{\mathrm{b}}$ Determined by ${ }^{1} \mathrm{H}$ NMR spectroscopy.

With the promising initial result in hand, we were keen to enhance the performance of our emerging iridium catalyst system as applied to this alkyne dimerization. Our goal was to increase the yield of the regioselective head-tohead coupling process whilst simultaneously improving the observed stereoselection. In this regard, through the stabilization of key reaction intermediates and the promotion of a certain reaction pathway, it is known that the addition of specific ligands within such transition-metalmediated processes can enhance alkyne coupling efficiency and selectivity. ${ }^{6,7,8 c, d}$ As such, we probed the use of various additives within our developing system, with a range of representative results displayed in Table 2. As shown by entry 2 (Table 2), the dimerization of phenylacetylene proceeded very effectively in the presence of tribenzylphosphine $\left(\mathrm{Bn}_{3} \mathrm{P} ; 30 \mathrm{~mol} \%\right)$, with a much improved yield of $82 \%$ being obtained, coupled with enhanced levels of $Z$ selectivity. Performing similar processes with $\mathrm{Bn}_{3} \mathrm{P}$ under more forcing reaction conditions (sealed tube or microwave) did not offer any improvement in terms of yield or selectivity. It has previously been reported that altering the nature of phosphine additives has a pronounced effect on the dimerization stereoselectivity observed. ${ }^{8 c}$ Accordingly, an alternative electron-rich phosphine (tri- butylphosphine) was employed within this study. However, this failed to induce prominent $Z$-selectivity; as noted in Table 2, entry 5 , a reversal of stereoselectivity in favor of the $(E)$-enyne was displayed. Furthermore, alternative additives either delivered the product(s) in diminished yields or failed to promote the reaction at all (Table 2, entries 6-8).

Table 2 Additive Study

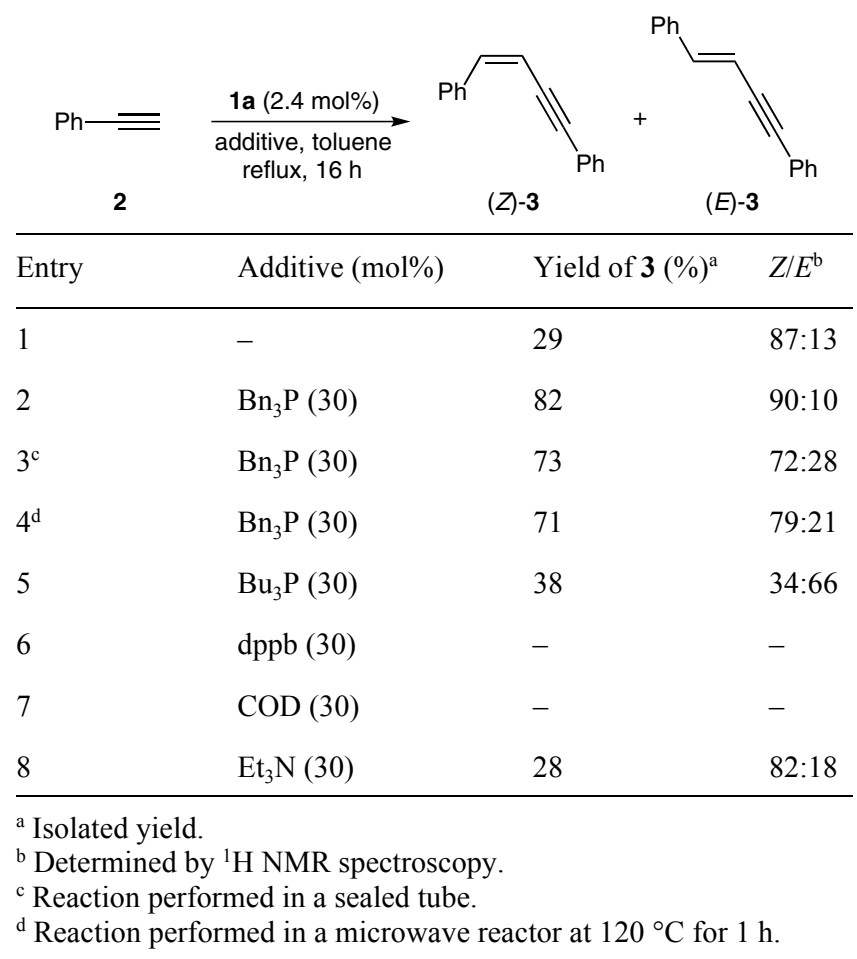

Following the establishment of this procedure with iridium complex 1a at relatively low catalyst loading, coupled with $\mathrm{Bn}_{3} \mathrm{P}$ additive, a number of alternative terminal alkyne substrates were examined (Table 3). Pleasingly, in every case, the head-to-head $(Z)$-enyne product was prepared in excess. Initially, we probed the applicability of our optimal conditions using 4-tolylacetylene (Table 3, entry 2) with an isolated yield of $72 \%$ and a $Z / E$ ratio of $81: 19$ being obtained. Our attention then turned to further substituted aryl alkynes, specifically containing para-substituted halogens. More specifically, many transition-metal catalysts promote protodehalogenation, and we were eager to test the ability of our catalyst to facilitate the desired transformation in a completely chemoselective manner. The homodimerization of 4-fluorophenylacetylene proceeded in an excellent yield with good stereocontrol (Table 3, entry 3). Especially pleasing was the ability of complex 1a to facilitate the homodimerization of 4-chlorophenylacetylene (Table 3, entry 4) and 4-bromophenylacetylene (Table 3, entry 5) in good yield with appreciable levels of stereoselectivity. The electronic nature of the substrates was investigated further with the electron-donating 4-methoxyphenylacetylene (Table 3 , entry 6 ) being reacted under the optimized conditions. Disappointingly, the desired products were formed in poor yield with only 
a slight bias towards the $(Z)$-enyne product; the majority of the mass balance in this instance was made up of unreacted starting alkyne. In contrast, the electron-withdrawing 4-trifluoromethylphenylacetylene underwent dimerization in good yield with the $(Z)$-enyne, again, being formed preferentially.

Table 3 Substrate Scope

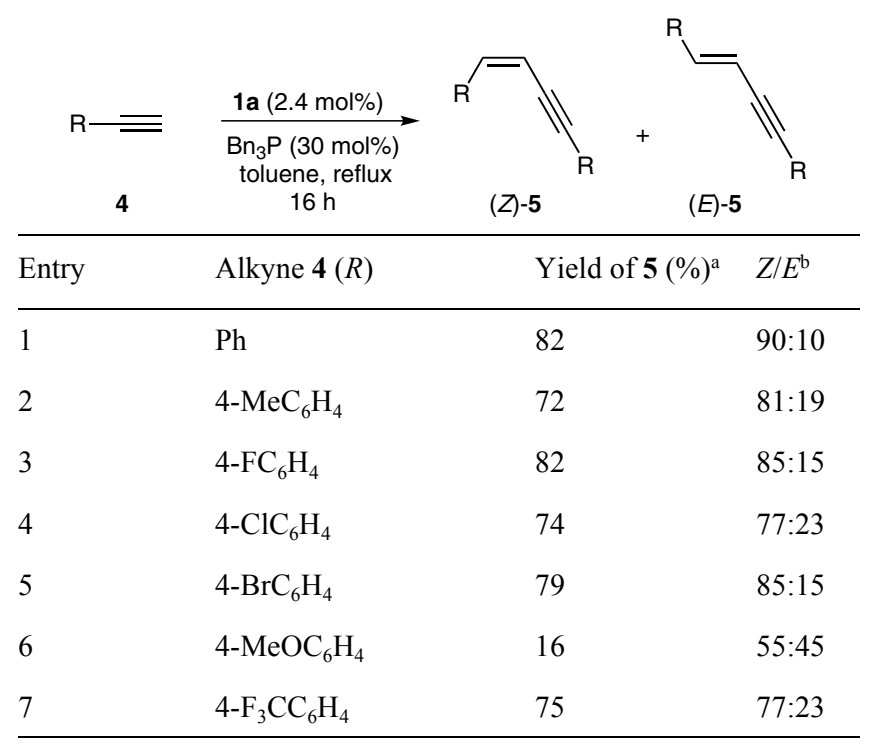

${ }^{\text {a }}$ Isolated yield.

${ }^{\mathrm{b}}$ Determined by ${ }^{1} \mathrm{H}$ NMR spectroscopy.

Based on our observed reaction products, as well as appreciation of previously elucidated pathways of similar transformations, ${ }^{8 \mathrm{c}, 11 \mathrm{a}, 17}$ we propose that the reaction proceeds by the pathway described below (Scheme 3 ). The iridium complex undergoes an initial oxidative addition, with terminal alkyne $\mathbf{I}$, to form complex $\mathbf{a}$. It is believed that the electron-rich ligand environment then facilitates a subsequent oxidative addition of a second alkyne unit to deliver intermediate b; such $\operatorname{Ir}(\mathrm{V})$ species have been the subject

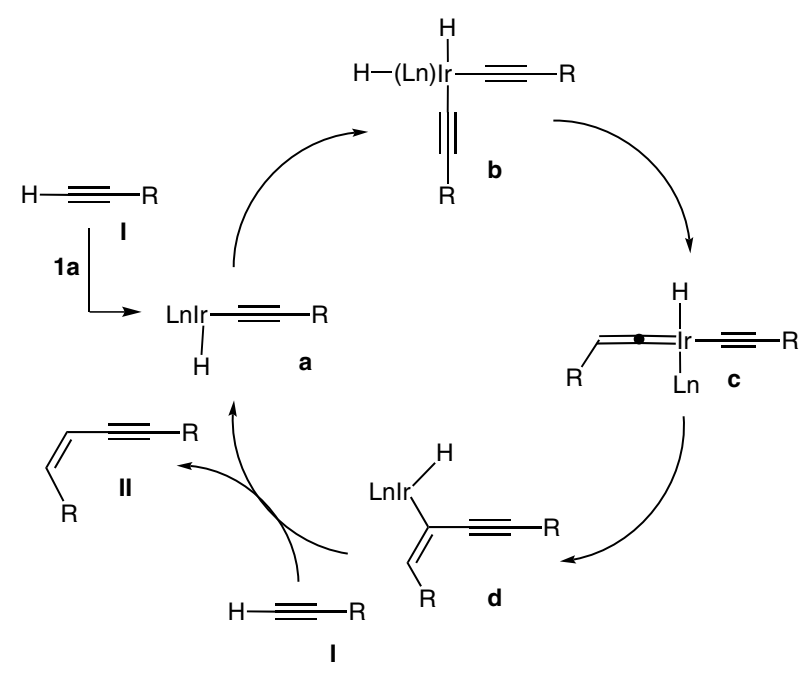

Scheme 3 Potential mechanistic pathway of increasing attention in recent years. ${ }^{18}$ Following this, in a well-precedented process, ${ }^{11 \mathrm{a}, 19}$ complex $\mathbf{b}$ can isomerize to the vinylidene complex $\mathbf{c}$ by intraligand hydrogen transfer. Intramolecular migration of the alkyne unit onto the $\alpha$-carbon of the vinylidene moiety results in formation of the cis-enyne iridium species d. As supported by the detailed observations of Wakatsuki when employing $\mathrm{Ru}$ complexes within related processes, ${ }^{11 \mathrm{a}}$ the $c i s$ form of the enyne unit within $\mathbf{d}$ is believed to be favored to avoid any repulsive interactions between the (alkenyl) $\mathrm{R}$ group and the specific bulky ligand sphere around Ir, which would occur in the trans form. The cycle is completed by protodemetalation to provide the desired product II and returning intermediate a. Mechanistic studies relating to the use of our emerging iridium catalysts within a series of synthetic transformations are presently ongoing within our laboratories.

In summary, as part of a program of work within our laboratory to expand the applicability of novel iridium complexes 1, we have now developed a catalytic system for effective alkyne dimerization. As promoted by the electron-rich nature and combined steric bulk of the ligand set within the catalyst system, the established method delivers specifically the head-to-head coupled products in a $Z$ selective process. Under the optimized reaction conditions, complex 1a facilitates the homodimerization of a range of aryl alkynes with excellent levels of regiochemical control.

\section{Representative Experimental Procedure (Table 3, Entry 1)}

To a flame-dried, $\mathrm{N}_{2}$-purged, three-necked round-bottom flask, fitted with a condenser, was added phenylacetylene $(100 \mathrm{mg}, 0.98$ mmol), complex 1a (25 mg, $0.0237 \mathrm{mmol}, 2.4 \mathrm{~mol} \%)$, tribenzylphosphine $(97 \mathrm{mg}, 0.32 \mathrm{mmol})$, and dry toluene $(3.0 \mathrm{~mL})$. The reaction mixture was heated to reflux and allowed to stir for $16 \mathrm{~h}$. After this time, the reaction mixture was concentrated in vacuo, and the crude product was purified by silica column chromatography (eluent: $\mathrm{Et}_{2} \mathrm{O}-$ hexane, 5:95) to yield the dimerized product ( $82 \mathrm{mg}$, $82 \%$ yield). The product distribution was confirmed by analysis of the ${ }^{1} \mathrm{H}$ NMR spectrum to be $90: 10 Z / E$. More specifically, the ratio of products was established by integration of the specific olefinic proton signals and comparison with literature data. ${ }^{6,13,20,21}$

(Z)-1,4-Diphenylbut-1-ene-3-yne 6,13,20,21 $^{-1}$

IR $\left(\mathrm{CH}_{2} \mathrm{Cl}_{2}\right): 3053,3031,1487 \mathrm{~cm}^{-1} .{ }^{1} \mathrm{H} \mathrm{NMR}\left(400 \mathrm{MHz}, \mathrm{CDCl}_{3}\right)$ : $\delta=7.95(\mathrm{~d}, 2 \mathrm{H}, J=7.6 \mathrm{~Hz}, \mathrm{ArH}), 7.51-7.32(\mathrm{~m}, 8 \mathrm{H}, \mathrm{ArH}), 6.73$ $(\mathrm{d}, 1 \mathrm{H}, J=11.8 \mathrm{~Hz}$, olefinic $\mathrm{CH}), 5.92(\mathrm{~d}, 1 \mathrm{H}, J=11.8 \mathrm{~Hz}$, olefinic $\mathrm{CH}) \mathrm{ppm} .{ }^{13} \mathrm{C}$ NMR $(100 \mathrm{MHz}): \delta=138.6,136.4,131.5,128.7$, $128.6,128.5,128.3,126.3,123.3,107.4,97.4,88.7$ ppm.

Olefinic ${ }^{1} \mathrm{H}$ NMR signals used to determine product ratio:

(Z)-Enyne: ${ }^{6,13,20,21} 6.73(\mathrm{~d}, J=11.8 \mathrm{~Hz})$ and $5.92(\mathrm{~d}, J=11.8 \mathrm{~Hz})$ ppm.

(E)-Enyne:6,21 $7.06(\mathrm{~d}, J=16.2 \mathrm{~Hz})$ and $6.40(\mathrm{~d}, J=16.2 \mathrm{~Hz}) \mathrm{ppm}$.

\section{Acknowledgment}

The authors are grateful to the EPSRC for funding (CDF) and the EPSRC Mass Spectrometry Service, University of Wales, Swansea, for analyses. We also thank Mr. Alvaro Mallagaray, Universidad San Pablo CEU, Spain, for input to the initial stages of this program. 


\section{References and Notes}

(1) Trost, B. M. Angew. Chem., Int. Ed. Engl. 1995, 34, 259.

(2) Nicolaou, K. C.; Dai, W. M.; Tsay, S. C.; Estevez, V. A.; Wrasidlo, W. Science 1992, 256, 1172.

(3) Liu, Y.; Nishiura, M.; Wang, Y.; Hou, Z. J. Am. Chem. Soc. 2006, $128,5592$.

(4) Zhang, L.; Sun, S.; Kroll, J.; Luo, Y. Synlett 2012, 23, 54.

(5) (a) Trost, B. M.; Sorum, M. T.; Chan, C.; Harms, A. E.; Ruhter, G. J. Am. Chem. Soc. 1997, 119, 698. (b) Lucking, U.; Pfaltz, A. Synlett 2000, 1261.

(6) Midya, G. C.; Paladhi, S.; Dhara, K.; Dash, J. Chem. Commun. 2011, 47, 6698.

(7) Ogoshi, S.; Ueta, M.; Oka, M. A.; Kurosawa, H. Chem. Commun. 2004, 2732.

(8) (a) Jun, C.; Zheng, L.; Crabtree, R. H. Tetrahedron Lett. 1992, 33, 7119. (b) Ogata, K.; Toyota, A. J. Organomet. Chem. 2007, 692, 4139. (c) Ohmura, T.; Yorozuya, S. I.; Yamamoto, Y.; Miyaura, N. Organometallics 2000, 19, 365. (d) Ogata, K.; Oka, O.; Toyota, A.; Suzuki, N.; Fukuzawa, S. I. Synlett 2008, 2663.

(9) Platel, R. H.; Schafer, L. L. Chem. Commun. 2012, 48, 10609.

(10) Gevorgyan, V.; Rubin, M.; Sromek, A. W. Synlett 2003, 2265.

(11) (a) Wakatsuki, Y.; Yamazaki, H.; Kumegawa, N.; Satoh, T.; Satoh, J. Y.J. Am. Chem. Soc. 1991, 113, 9604. (b) Yi, C. S.; Liu, N. Organometallics 1996, 15, 3968.

(12) (a) Katagiri, T.; Tsurugi, H.; Satoh, T.; Miura, M. Chem. Commun. 2008, 3405. (b) Melis, K.; De Vos, D.; Jacobs, P.; Verpoort, F. J. Organomet. Chem. 2002, 659, 159.
(13) Nishiura, M.; Hou, Z.; Wakatsuki, Y.; Yamaki, T.; Miyamoto, T. J. Am. Chem. Soc. 2003, 125, 1184.

(14) (a) Brown, J. A.; Irvine, S.; Kennedy, A. R.; Kerr, W. J.; Andersson, S.; Nilsson, G. N. Chem. Commun. 2008, 1115. (b) Nilsson, G. N.; Kerr, W. J. J. Labelled Compd. Radiopharm. 2010, 53, 662. (c) Complexes 1a-c are available commercially from Strem Chemicals.

(15) (a) Crabtree, R. H.; Felkin, H.; Morris, G. E. J. Organomet. Chem. 1977, 141, 205. (b) Crabtree, R. H. Acc. Chem. Res. 1979, 12, 331. (c) Hesk, D.; Das, P. R.; Evans, B. J. Labelled Compd. Radiopharm. 1995, 36, 497. (d) Ellames, G. J.; Gibson, J. S.; Herbert, J. M.; McNeill, A. H. Tetrahedron 2001, 57, 9487.

(16) Bennie, L. S.; Fraser, C. J.; Irvine, S.; Kerr, W. J.; Andersson, S.; Nilsson, G. N. Chem. Commun. 2011, 47, 11653.

(17) (a) Schäfer, M.; Mahr, N.; Wolf, J.; Werner, H. Angew. Chem., Int. Ed. Engl. 1993, 32, 1315. (b) Wakatsuki, Y.; Yamazaki, H.; Kumegawa, N.; Johar, P. S. Bull. Chem. Soc. Jpn. 1993, 66, 987.

(18) (a) Webster, C. E.; Hall, M. B. Coord. Chem. Rev. 2003, 238-239, 315. (b) Kawamura, K.; Hartwig, J. F. J. Am. Chem. Soc. 2001, 123, 8422. (c) Meredith, J. M.; Robinson, R. Jr.; Goldberg, K. I.; Kaminsky, W.; Heinekey, D. M. Organometallics 2012, 31, 1879.

(19) (a) Bruce, M. I. Chem. Rev. 1991, 91, 197. (b) Bruce, M. I.; Swincer, A. G. Adv. Organomet. Chem. 1983, 22, 59.

(20) Kuang, C.; Yang, Q.; Senboku, H.; Tokuda, M. Tetrahedron 2005, 61, 4043.

(21) Galli, C.; Gentili, P.; Rapport, Z. J. Org. Chem. 1994, 59, 6786 . 